by C. F. Lee', J. J. Hou ${ }^{2}$ and H. Ye

\title{
The movement potential of the major faults in Hong Kong area
}

\author{
1. Department of Civil and Structural Engineering, The University of Hong Kong. Hong Kong \\ 2. Department of Geology. Peking University, Beijing I00871, China \\ 3. Institute of Geology, State Seismological Bureau, Beijing 100029, China
}

The major faults in Hong Kong and its adjacent region can be classified into three sets, striking east-northeast, northeast and northwest, respectively. In this paper, we propose a theoretical model to evaluate the fault movement potential (FMP) based on the relationship between fault geometrical characteristics and regional tectonic stress field. The results show that the east-northeast striking Dangan Islands fault zone and the northwest striking Lau Fau Shan-East Lamma Channel fault zone are of the highest movement potentials in the area. Their intersecting area located to the east of the Dangan Island is inferred to have the possibility of generating destructive earthquakes. To the north, the movement potentials of the northeast striking Lau Fau Shan fault,
Lo Wu fault and San Tin fault of the Lo Wu-Tuen Mun fault zone, especially their converging part near Lo $W u$, are also relatively high.

\section{Introduction}

Hong Kong is located in the Southeast Coastal Seismic Belt of China. The landforms in Hong Kong and its adjacent region are mainly controlled by three sets of faults, striking east-northeast, northeast, northwest, respectively (Figure 1). The questions to be addressed in this paper are: (1) What are the activity levels of these faults? and (2) Will these faults cause destructive earthquakes? Previous work regarding to these topics was mainly based on geological analyses (Liu, 1981; Lee. 1987; Ding et al., 1992; Ren et al., 1996; Zhong et al., 1996; Lai et al., 1996). However, it is difficult to eval-

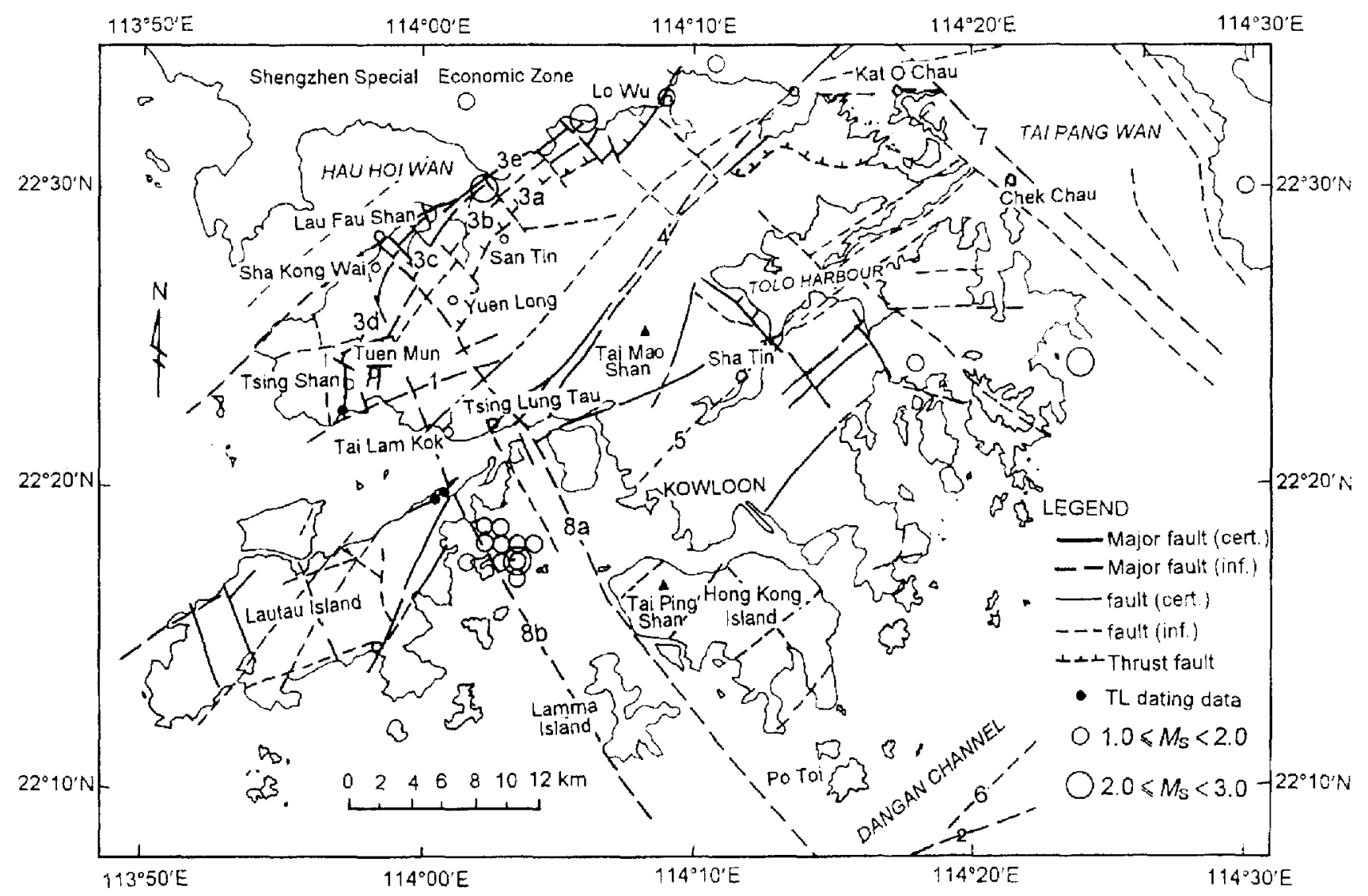

Figure 1 The major faults and epicenters of modern small earthquakes (1972-1995) in Hong Kong. Note: 1. Tsing Shan Wan-Tai Po Hoi Fz., 2. Dangan Islands Fz., 3. Lo Wu--Tuen Mun Fz.,. 3a. San Tin Fs, 3b. Lo Wu Fs, 3c. Tuen Mun Fs, 3d. Tsing Shan Fs, 3e. Lau Fau Shan Fs, 4. Sha Tau kok-Pui O Wan Fz., 5. Lai Chi Kok-Tolo Channel Fz., 6. Po Toi Fz., 7. Kat O Chau-Chek Chau Fz., 8. Lau Fau Shan--East Lamma Channel Fz.,: 8a. Lau Fau Shan-Tsing Lung Tau Fs, 8b. Sha Kong Village-Tai Lam Kok Fs. 
uate the fault activity just based on geological analysis because the surface expressions of recent fault activity in South China including Hong Kong are commonly covered or obscured. In this paper, we propose an alternative method to evaluate fault activity by considering the mechanical relationships between fault geometry and regional tectonic stress field. This method has been used to evaluate the fault movement potentials of all the major faults in Hong Kong and its adjacent region, and the results are consistent with the historical seismic records and present-day micro-earthquake activity.

\section{The major faults in Hong Kong and its adjacent region}

Faults are well developed in Hong Kong and its adjacent region. They were classified into three sets: east-northeast-striking, northeast-striking and northwest-striking

\section{The east-northeast-striking fault set}

The east-northeast striking fault set is the major Caledonian-torecent fault set in Hong Kong region. The faults in this set are multistaged active faults inferred to have significant effects on the development of the Outer Pearl River Estuary Basin in the northern part of South China Sea during the Quaternary. Striking $60^{\circ}-70^{\circ}$ with high dip angles, this fault set can be subdivided into the Tsing Shan WanTai Po Hoi fault zone (1) and the Dangan Islands fault zone (2). Of these, the former offset the northeast-striking Tsing Shan fault (3-d) and the Tuen Mun fault (3-c). Thermoluminescence dating from the sample collected at Yim O Tuk in a small fault located to the north of Lantau Island yielded an age of $82,000 \pm 6.800$ years B. P. This suggests that the east-northeast striking faults were still active in the early stage of the Late Pleistocene.

\section{The northeast striking-fault set}

This fault set comprises four fault zones striking $30^{\circ}-50^{\circ}$ with high dip angles. Among them, the Lo Wu-Tuen Mun fault zone (3) in the northwest "New territories" and the Po Toi fault zone (6) to the south of Hong Kong Island are the major fault zones. The Sha Tau KokPui $O$ Wan fault zone (4) and the Lai Chi Kok-Tolo Channel fault zone (5) are the two minor fault zones between the two major fault zones. The fault set forms the western extension of the Lian Hua Shan Fault System. Basic and ultrabasic rocks along the fault set suggest that this fault set cut deeply up to upper mantle. Samples collected at Wu Tip Wan along Lo Wu-Tuen Mun fault zone yielded an age of $265,500 \pm 21,000$ years B. P. by thermoluminescence dating.

\section{The northwest-striking fault set}

The faults of this set are well exposed and can be traced intermittently for a long distance in the direction of $310^{\circ}-330^{\circ}$. They are the most recently active faults because they displaced the faults striking in other directions. In this set, there are two major fault zones, the Kat O Chau-Chek Chau fault zone (7) in the east of Kowloon peninsula and the Lau Fau Shan-East Lamma Channel fault zone (8) in the west of the peninsula. The latter can be subdivided into two parallel branches, the Lau Fau Shan-Tsing Lung Tau fault (8-a) and the Sha Kong Village-Tai Lam Kok fault (8-b). A sample from Yim O Tuk to the north of Lantau Island was dated to be $33,300 \pm 2,700$ years B. $P$. by thermoluminescence dating, indicating that the fault zone may have been active since Late Pleistocene period.

In summary, east-northeast-striking faults were formed earlier than the others and active in different tectonic stages until Late Pleistocene period. Northwest-striking faults were formed last and displaced the other striking faults. Northeast-striking faults were also active in middle Pleistocene. These faults are characterized by negative landforms and are inferred to control the development of channels, gullies and drainage patterns in the region.

In the following sections, we will evaluate the earthquake risk along these faults, and discuss which fault is most favored to move under the influence of present-day tectonic stress field. We make this evaluation based on the relationships between tectonic stress orientation and fault geometric properties. To test our model, we will compare the results with present-day micro-earthquake activity in Hong Kong and its adjacent region.

\section{Theoretical model for analysis of fault movement potential}

The fault movement potential (FMP) is closely related to tectonic stress $(\sigma)$, fault plane geometry $(G)$ and the physical property of the medium within and on both sides of the fault (P). FMP is the function of these factors:

$$
\mathrm{FMP}=\mathrm{f}(\sigma, \mathrm{G}, \mathrm{P})
$$

Although a geological medium is generally heterogeneous and very complicated, it can be taken as homogeneous and isotropic in statistical view. Based on this consideration, and for the purpose of simplification in the theoretical derivation, we take the geological medium containing the faults as a homogeneous, isotropic and elastic material. Thus, fault movement potential can be simplified as:

$$
F M P=f(\sigma, G)
$$

To consider the influence of tectonic stress orientation and fault geometry on fault seismicity, Lokajicek et al. (1988) conducted laboratory experiments using block models. Their results showed that changes in fault inclination led to remarkable changes both in the recurrence time intervals between individual seismic events and in the amount of seismic energy; for some dip angles, the fault seismic activity vanishes. To prove the results of the laboratory experiments, He (1989) carried out a theoretical analysis and showed that faults can slip when the angles between the orientations of the maximum compressive principal stress and fault strike are between $20^{\circ}$ and $70^{\circ}$. However, there are many exceptions in applying this model to natural fault systems. We consider that the exceptions are caused by the limitation of their two-dimensional consideration. In reality, fault planes are not always vertical and the orientations of the maximum compressive principal stress are also not always horizontal. In this paper, we consider this problem in three-dimensions using the Mohr stress circle.

\section{Theoretical model}

Mechanically, the most important factors that affect the onset of slip movement on a pre-existing fault are (suppose compressional stress is positive):

1) the difference between the maximum principal stress $\left(\sigma_{1}\right)$ and the minimum principal stress $\left(\sigma_{3}\right):\left(\sigma_{1}-\sigma_{3}\right)$. This determines the diameter of the Mohr circle.

2) the sum of the maximum principal stress $\left(\sigma_{1}\right)$ and the minimum principal stress $\left(\sigma_{3}\right):\left(\sigma_{1}+\sigma_{3}\right)$. This determines the location of Mohr circle.

The angle between the normal to the fault plane and the maximum principal stress $\left(\sigma_{1}\right)$ is denoted as $\theta$. The lower and the upper limits of $\theta$ between which the fault can slip, are denoted as $\theta_{1}$ and $\theta_{2}$ respectively. The symbol $\theta_{0}$ represents the special value of $\theta$ at which fault slip is most likely to occur, $\varphi$ is the angle of internal friction of the fault, $\tau_{0}$ is the internal cohesion of the fault, and $T_{0}$ is the point where tensile fracture occurs. First, we calculate the angle $\left(\theta_{0}\right)$ at which the fault is most likely to slip. According to the sine theorem and Figure 2, we have 


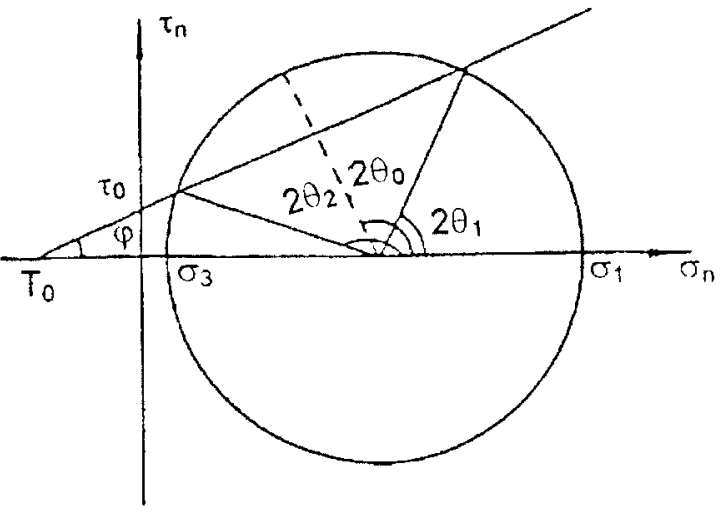

Figure 2 Mohr circle representation of stress states during fault slipneeded by fault slip.

$$
\frac{\sigma_{1}-\sigma_{3}}{\sigma_{1}+\sigma_{3}+2 \tau_{0} \operatorname{ctg} \varphi}=\frac{\sin \varphi}{\sin (2 \theta-\varphi)}
$$

take the derivative of stress $(\sigma)$ with respect to the angle $\theta$, and let the derivative equal to zero, we get

$$
\cos (2 \theta-\varphi)=0 . \quad \theta_{0}=45^{\circ}+\varphi / 2
$$

Then. we calculate the lower and the upper limits of the angle $\theta$ hetween which fault slip can occur. From equation (3) we have

$$
\sin (2 \theta-\varphi)=\frac{\sigma_{1}+\sigma_{3}+2 \tau_{()} \operatorname{tg} \varphi}{\sigma_{1}-\sigma_{3}} \cdot \sin \varphi
$$

When $\sigma_{3} \rightarrow T_{0}, \sigma_{1}+\sigma_{3}+2 \tau_{0} \operatorname{ctg} \varphi \rightarrow \sigma_{1}-\sigma_{3}$ from Figure 2, the range of $\theta$ is maxinum. Therefore, we can get:

and

$$
\sin (2 \theta-\varphi)=\sin \varphi
$$

The friction factor on a brittle fracture surface is usually $0.5-0.8$ (Wang et al. 1979). which corresponds to

$$
\varphi=27-39
$$

For convenience in calculation, take $\varphi=30$, which gives

$$
\theta=\left\{\begin{array}{l}
\theta_{0}=60 \\
\theta_{1} \rightarrow \varphi \\
\theta_{2} \rightarrow \pi / 2
\end{array}\right.
$$

This means that when $30<\theta<90$, a fault might slip; when $\theta=60$. the fault slips most easily. If $\theta \leq 30$ or $\theta \geq 90$, the fault can not slip.

To quantify the relationship between fault movement potential (FMP) and the angle $\theta$, we define FMP as a normalized factor by the following

$$
\mathrm{FMP}= \begin{cases}0, & \theta \in[0,30] \\ \frac{\theta-30}{30^{\circ}}, & \theta \in\left(30^{\circ}, 60\right] \\ 1-\frac{\theta-60}{30^{\circ}}, & \theta \in(60,90]\end{cases}
$$

\section{Calculation of angle $\theta$}

If we know the direction of normal $\left(\gamma_{1}\right)$ to a fault plane and its dip angle $\left(\beta_{1}\right)$. and the orientation $\left(\gamma_{2}\right)$ of the maximum principal stress and its dip angle $\left(\beta_{2}\right)$, then $\theta$ can be calculated from their geometrical relationships (Figure 3 ).

Suppose $\gamma$ to be the the azimuth of a straight line and $\beta$ to be its dip angle, then the straight line can be expressed as

$$
\begin{aligned}
\mathrm{l} & =\mathrm{OA}=\cos \beta \cos \gamma \\
\mathrm{m} & =\mathrm{CB}=\sin \beta \\
\mathrm{n} & =\mathrm{AB}=\cos \beta \sin \gamma
\end{aligned}
$$

and the vector $\mathrm{N}=[1, \mathrm{~m}, \mathrm{n}]$. is the direction of the straight line. Therefore, the angle between two straight lines can be calculated as

$$
\cos \theta=\cos \beta_{1} \cos \beta_{2} \cos \left(\gamma_{1}-\gamma_{2}\right)+\sin \beta_{1} \sin \beta_{2}
$$

The value of $\beta_{2}$ should be negative when taking the angle of $\sigma_{1}$ axis as elevation.

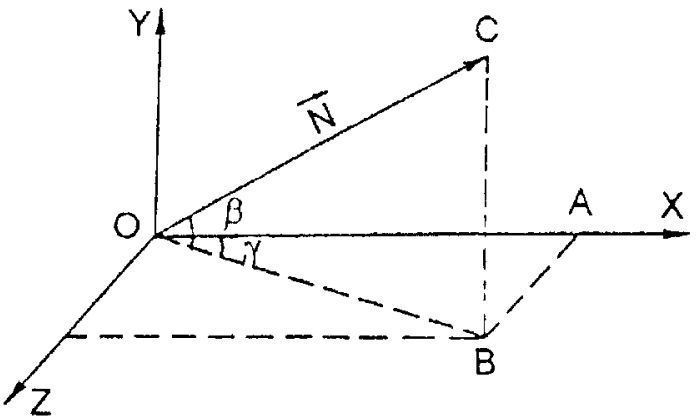

Figure 3 The expression of a straight line in three dimensions.

\section{Fault movement potentials in Hong Kong and its adjacent region}

\section{Regional tectonic stress orientations}

Tectonic stress means an additional stress to lithostatic stress state. in other words, the part of stress deviated from lithostatic stress. Earthquake focal mechanism solution is one of the commonly used methods in the study of contemporary tectonic stress field. Although the orientation of the maximum principal compressive stress obtained from the focal mechanism solution of a strong earthquake represents the characteristics of large regional tectonic stress field (Lanzhou Institute of Seismology, State Seismological Bureau of China, 1992), some of the focal mechanism solutions of macroseisms reflect more complicated deep structure condition and stress feature, which means an exceptional stress field in instantaneous focal process in addition to regional tectonic stress field in earthquake genetic process, and the focal mechanism solution of a single small earthquake has random features. Fortunately, synthetic focal mechanism solutions of many small earthquakes may reflect a regional tectonic stress state. Therefore, we analyzed both of the focal mechanism solutions of large earthquakes and the average solutions of small earthquakes in order to get the general configuration of the regional stress state in Hong Kong and its adjacent area (Table 1). The statistical result shows that the average azimuth of $\mathrm{P}$ axes is $110^{\circ}$ at elevation angle 8 .

\section{Fault movement potential results and their analysis}

The fault movement potentials of the major faults in Hong Kong and its adjacent region are calculated using the above equations and the regional stress orientation as well as the fault plane attitudes. The results are shown in Table 2.

1. The east-northeast striking Tsing Shan Wan-Tai Po Hoi fault zone has complicated geometric shapes, and the angle between the normal to the fault plane and the compressive principal stress along this fault zone changes remarkably. The fault movement potential of this fault zone ranges from middle to high, suggesting that this fault zone has the potential for generating earthquakes. Most interestingly, the Dangan Islands fault zone, a segment of the Tsing Shan Wan-Tai Po Hoi fault zone, is calculated to have the highest movement potential of 1.0 , and a destructive earthquake $(\mathrm{Ms}=5.75$, June 23,1874 ) occurred right on this fault zone in the sea area to the east 
Table 1 Focal mechanism solution of Hong Kong and its adjacent area

\begin{tabular}{|c|c|c|c|c|c|c|c|c|c|c|}
\hline \multirow{2}{*}{$\frac{\text { Date }}{1918.2 .13}$} & \multirow{2}{*}{$\frac{\text { Location }}{\text { Nanyue, Guangdong }}$} & \multirow{2}{*}{$\frac{\phi N}{23.5}$} & \multirow{2}{*}{$\frac{\lambda \mathrm{E}}{117.0}$} & \multirow{2}{*}{$\frac{M}{7.25}$} & \multicolumn{2}{|c|}{$\mathrm{P}$} & \multicolumn{2}{|c|}{$\mathrm{T}$} & \multicolumn{2}{|c|}{$\mathrm{N}$} \\
\hline & & & & & 83 & 2 & 352 & 18 & 189 & 80 \\
\hline 1962.3 .19 & Heyuan, Guangdong & 23.7 & 114.7 & 6.1 & 287 & 9 & 17 & 6 & 141 & 80 \\
\hline 1964.9 .23 & Heyuan, Guangdong & 23.7 & 114.7 & 5.3 & 78 & 32 & 338 & 17 & 225 & 53 \\
\hline 1965.10 .7 & Xisha & & & 5.9 & 355 & 5 & 264 & 76 & 85 & 14 \\
\hline 1966.9 .26 & $\begin{array}{l}\text { Shantou off shore, } \\
\text { Guangdong }\end{array}$ & 22.3 & 117.5 & 5.3 & 256 & 10 & 351 & 25 & 121 & 63 \\
\hline 1969.7 .26 & Yangjiang,Guangdong & 21.7 & 111.8 & 6.4 & 299 & 22 & 206 & 7 & 100 & 67 \\
\hline 1971.8 .21 & Nanpeng, Guangdong & 23.1 & 117.3 & 3.7 & 145 & 37 & 44 & 13 & 298 & 51 \\
\hline 1972.4 .6 & South China Sea & & & 5.5 & 328 & 6 & 227 & 65 & & \\
\hline 1972.5 .29 & Fugang, Guangdong & 23.8 & 113.6 & 3.1 & 159 & 19 & 55 & 35 & 273 & 49 \\
\hline 1972.12 .18 & Heyuan, Guangdong & 23.7 & 114.7 & 4.5 & 103 & 8 & 13 & 8 & 238 & 80 \\
\hline 1973.7 .16 & Haifeng, Guangdong & $\begin{array}{l}\text { avera } \\
\text { eartho }\end{array}$ & $\begin{array}{l}\text { nall } \\
\text { olutions }\end{array}$ & & 101 & 50 & 3 & 8 & 266 & 40 \\
\hline 1974.2. 22 & $\begin{array}{l}\text { Lufeng off shore } \\
\text { Guangdong }\end{array}$ & 22.0 & 115.5 & 4.0 & 73 & 28 & 328 & 28 & 200 & 50 \\
\hline 1974.4.24 & Yangjiang. Guangdong & $\begin{array}{l}\text { avera } \\
\text { eartho }\end{array}$ & $\begin{array}{l}\text { nall } \\
\text { olutions }\end{array}$ & & 102 & 11 & 193 & 4 & 303 & 78 \\
\hline 1975.2 .11 & Yangjiang, Guangdong & 21.7 & 111.8 & 3.4 & 88 & 15 & 335 & 58 & 186 & 29 \\
\hline $1973-1977$ & Shantou, Guangdong & $\begin{array}{l}\text { statist } \\
\text { earthc }\end{array}$ & mall & & 290 & 36 & 191 & 13 & 38 & 51 \\
\hline 1979.9 .14 & South China Sea & & & 5.2 & 292 & 23 & 68 & 59 & & \\
\hline 1992. 2.18 & Nanri Island & & & 5.2 & 92 & 51 & 234 & 32 & 332 & 20 \\
\hline
\end{tabular}

(moditied from Liu, 1981: Ren et al., 1996)

Table 2 The calculation of fault movement potential in Hong Kong region

\begin{tabular}{|c|c|c|c|c|}
\hline No. and name of fault zone & attitude of fault & normal line of fault plane & $\theta$ & FMP \\
\hline \multicolumn{5}{|l|}{ 1. Tsing Shan Wan } \\
\hline -Tai Po Hoi Fz & $60^{\circ}-70^{\circ} / \mathrm{NW} \angle 50^{\circ}-65^{\circ}$ & $330^{\circ}-340^{\circ} \angle 25^{\circ}-40^{\circ}$ & $42^{\circ}-55^{\circ}$ & $0.4-0.8$ \\
\hline 2. Dangan Islands Fz & $70^{\circ} / \mathrm{SE} \angle 60^{\circ}$ & $160^{\circ} \angle 30^{\circ}$ & $61^{\circ}$ & 1.0 \\
\hline $\begin{array}{l}\text { 3. Lo } \mathrm{Wu}-\text {-Tuen Mun } \mathrm{Fz} \\
\text { a. San Tin Fs } \\
\text { b. Lo WuFs }\end{array}$ & $40^{\circ} / \mathrm{NW} \angle 35^{\circ}-50^{\circ}$ & $310^{\circ} \angle 40^{\circ}-55^{\circ}$ & $37^{\circ}-50^{\circ}$ & $0.2-0.7$ \\
\hline NE segment & $50^{\circ}-55^{\circ} / \mathrm{NW} \angle 58^{\circ}$ & $320^{\circ}-325^{\circ} \angle 32^{\circ}$ & $37-41$ & $0.2-0.4$ \\
\hline \multicolumn{5}{|l|}{ c. Tuen Mun Fs } \\
\hline NE segment & $40^{\circ} / \mathrm{NW} \angle 50^{\circ}-67^{\circ}$ & $310^{\circ} \angle 23^{\circ}-40^{\circ}$ & $21^{\circ}-37^{\circ}$ & $0.0-0.2$ \\
\hline $\begin{array}{l}\text { SW segment } \\
\text { d. Tsing Shan Fs }\end{array}$ & $15^{\circ} / \mathrm{NW} \angle 40^{\circ}-50^{\circ}$ & $285^{\circ} \angle 40^{\circ}-50^{\circ}$ & $33^{\circ}-43^{\circ}$ & $0.1-0.4$ \\
\hline NE segment & $50^{\circ}-55^{\circ} / \mathrm{NW} \angle 50^{\circ}-67^{\circ}$ & $320^{\circ}-325^{\circ} \angle 23^{\circ}-40^{\circ}$ & $33^{\circ}-45^{\circ}$ & $0.1-0.5$ \\
\hline SW segment & $10^{\circ}-20^{\circ} / \mathrm{NW} \angle 40^{\circ}-50^{\circ}$ & $280^{\circ}-290^{\circ} \angle 40^{\circ}-50^{\circ}$ & $34^{\circ}-42^{\circ}$ & $0.1-0.4$ \\
\hline e. Lau Fau Shan Fs & $60^{\circ} / \mathrm{NW} \angle 51^{\circ}-67^{\circ}$ & $330^{\circ} \angle 23^{\circ}-39^{\circ}$ & $41^{\circ}-48^{\circ}$ & $0.4-0.6$ \\
\hline \multicolumn{5}{|l|}{ 4. Sha Tau kok } \\
\hline $\begin{array}{l}\text { Pui O Wan Fz } \\
\text { 5. Lai Chi Kok }\end{array}$ & $30^{\circ}-50^{\circ} / \mathrm{NW} \angle 60^{\circ}-70^{\circ}$ & $300^{\circ}-320^{\circ} \angle 20^{\circ}-30^{\circ}$ & $15^{\circ}-36^{\circ}$ & $0.0-0.2$ \\
\hline \multicolumn{5}{|l|}{-Tolo Channel Fz } \\
\hline NE segment & $40^{\circ}-50^{\circ} / \mathrm{NW} \angle 83^{\circ}-85^{\circ}$ & $310^{\circ}-320^{\circ} \angle 5^{\circ}-7^{\circ}$ & $21^{\circ}-30^{\circ}$ & 0.0 \\
\hline SW segment & $40^{\circ}-50^{\circ} / \mathrm{SE} \angle 75^{\circ}-80^{\circ}$ & $130^{\circ}-140^{\circ} \angle 10^{\circ}-15^{\circ}$ & $27^{\circ}-37^{\circ}$ & $0.0-0.2$ \\
\hline 6. Po Toi Fz & $50^{\circ} / \mathrm{SE} \angle 60^{\circ}-70^{\circ}$ & $140^{\circ} \angle 20^{\circ}-30^{\circ}$ & $41^{\circ}-48^{\circ}$ & $0.4-0.6$ \\
\hline 7. Kat O Chau & & & & \\
\hline -Chek Chau Fz & $320^{\circ} / \mathrm{NE} \angle 50^{\circ}$ & $50^{\circ} \angle 40^{\circ}$ & $49^{\circ}$ & 0.6 \\
\hline $\begin{array}{l}\text { 8. Lau Fau Shan--East } \\
\text { Lamma Channel Fz } \\
\text { a. Lau Fau Shan }\end{array}$ & & & & \\
\hline $\begin{array}{l}\text {-Tsing Lung Tau Fs } \\
\text { b. Sha Kong Village }\end{array}$ & $330^{\circ} / \mathrm{NE} \angle 55^{\circ}$ & $60^{\circ} \angle 35^{\circ}$ & $64^{\circ}$ & 0.9 \\
\hline -Tai Lam Kok Fs & $340^{\circ} / \mathrm{SW} \angle 70^{\circ}$ & $250^{\circ} \angle 20^{\circ}$ & $41^{\circ}$ & 0.4 \\
\hline
\end{tabular}


of Dangan Islands. Therefore, it is highly possible that more destructive earthquakes would occur along this fault zone in the future.

2. The northeast striking fault zones are extensively distributed through Hong Kong and its adjacent region. This fault set is often diverging to southwest and converging to northeast. For example, the Lo Wu-Tuen Mun fault zone diverges to southwest in a fan shape branching into five secondary-faults with high movement potentials. Of them, the Lau Fau Shan fault, Lo Wu fault and San Tin fault are of high movement potentials up to 0.7 . Considering that there are many small earthquakes clustering along the northeastern parts of the faults (Figure 1), we believe that the converging area of the fault zones (near $\mathrm{Lo} \mathrm{Wu}$ ) is another place where major earthquakes are likely to occur. The other three northeast striking fault zones, Sha Tau Kok-Pui O Wan, Lai Chi Kok-Tolo Channel and Po Toi fault zones, are low in terms of movement potential.

3. The northwest striking Kat O Chau-Chek Chau fault zone has intermediate movement potential values, but the movement potentials of the northwest striking Lau Fau Shan-East Lamma Channel fault zone is relatively high. This is consistent with the fact that few earthquakes occur along the former and many small earthquakes occur at the intersection of the latter and the northeast striking Sha Tau Kok-Pui O Wan fault zone. Besides, the 1874 destructive earthquake occurred at the intersection of this fault zone with the eastnortheast striking Dangan Islands fault zone.

\section{Discussion and conclusions}

Seismicity is closely related to active Quaternary faults. This attracts many researchers to investigate the quantitative relationships between them. As a new parameter, FMP is defined to quantify earthquake risk along active faults and is formulated as a function of the fault geometry and the tectonic stress field. The contemporary movement potentials along fault zones of different orientations are different under the action of present-day regional west-northwest compressive stress field in Hong Kong and its adjacent region. The region where the northwest striking Lau Fau Shan-East Lamma Channel fault zone intersects with the east-northeast striking Dangan Islands fault zone is prone to destructive earthquakes since both of these two fault zones have high movement potentials. The movement potential of the northeast striking Lo Wu-Tuen Mun fault zone is also relatively high. But its southwestern segment is unlikely to cause major earthquakes because its divergence towards southwest may cause dispersion of strain energy. In contrast, the converging part of this fault zone at its northeastern segment, near Lo Wu, is expected to accumulate strain energy. This is another area with relatively high seismic potential.

\section{Acknowledgment}

We would like to thank Dr. K. W. Lai and Dr. C. J. N. Fletcher for their valuable support in the field investigation and helpful discussions concerning the fault activity in Hong Kong and its adjacent region, and thank Dr. Juliet Crider and Dr. Taixu Bai for their conscientiously reviewing the manuscript.

\section{References}

Ding, Y. Z., Liang, L. and Guo, Q. H. (1992). Seismic risk of fault zone tectonics in coastal area of South China, in Selected papers on Quaternary geology on southeast coastal zone of China: Seismological Press of China. pp. 1-10.
He, S. H. (1989). The effect of orientation and level of principal stress on fault movement: Crustal Deformation and Earthquake, 9(3): pp. 44-52.

Lai, K. W. and Langford, R. L. (1996). Spatial and temporal characteristics of major faults of Hong Kong. Seismicity in Eastern Asia: Geological Society of Hong Kong Bulletin (5): pp. 72-84.

Lanzhou seismological Institute, State Seismological Bureau of China (1992). Changma active fault zone: Seismological Press of China, pp. 186-200.

Lokajicek, T., Spicak, A. and Waniek, L. (1988). Tectonic stress orientation and the seismic regime of a single fault: Tectonophysics. 152: pp. 297-302.

Lee, C. M. (1987). A summary introduction of geology of Hong Kong: Guangdong Geology, 2(1): pp. 29-48.

Liu, Y. X. (1981). The analysis of fault tectonics in coastal region of South China: Seismological Press of China, pp. 65-84.

Ren, Z. H., Ren, B. T., Luo, Z. N., Chen, Y. M. and Zhong, Y. J. (1996). Study on activity of NEE trending tectonics on north margin of the South China Sea: Crustal Deformation and Earthquake.16(2): pp. 27-35.

Wang, R., Ding, Z. Y. and Yin, Y. Q. (1979). Introduction to solid mechanics: Geological Press of China.

Zhong, J. Q., Zhan, W. H., Gu, S. C. and Liu, H. L. (1996). Study on neotectonic movement and crustal stability in Pearl River Delta: South China: Journal of Seismology. 16(2): pp. 57-63.

Lee $C . F$. is presently Chair Professor in Geotechnical Engineering, Department of Civil and Structural Engineering, University of Hong Kong. He worked on a variety of nuclear power and hydroelectric power projects for Ontario Hydro, Canada between 1975 and 1993. His current interest includes seismic hazard and landslide hazard mitigation.

Hou Jianjun is Associate Professor and Director of the Seismotectonics Section, Department of Geology, Peking University. He was educated in Peking University where he completed both his undergraduate and doctoral degrees, and further studied in the University of California at Berkeley, US from 1987 to 88 . He is currently engaged in the study of active tectonics analysis of seismicity and geological hazard assessment.

\section{Ye Hong is Director of the Seismo- tectonics and Engineering Seismol- ogy Division, Institute of Geology, Chinese State Seismological Bureau, and Professor in Department of Geology, Peking University. $\mathrm{He}$ is currently Deputy Secretary-General of Geological Society of China. His current research interest includes seismotectonics and seismic hazard assessment, crustal stress field, envi- ronmental dynamics, application of artificial intelligence and GIS in geo-} science.
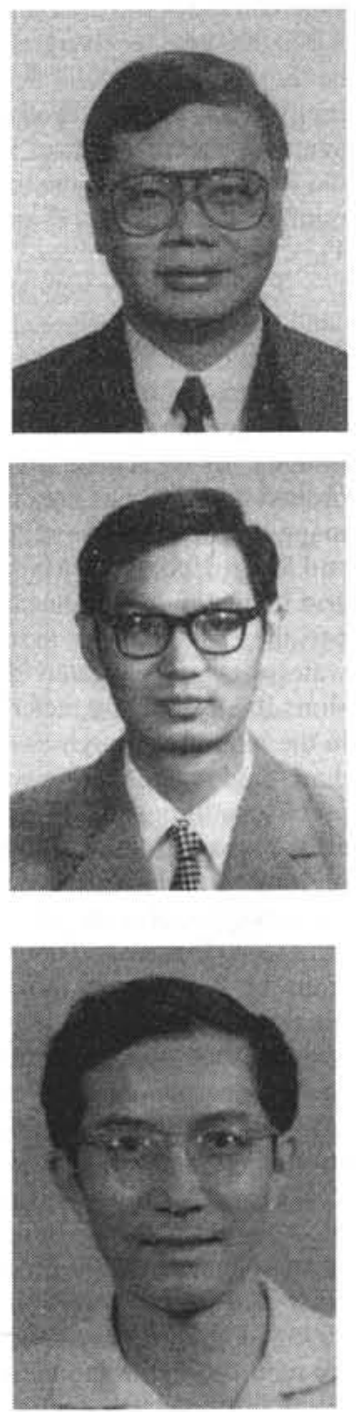